\title{
The Protection and Inheritance of Ancient Dwellings in Liu Jiaqiao Village under the Change of Times
}

\author{
Yuhan Dong, Yuan Gao \\ School of Architecture and Urban Planning, Huazhong University of Science and Technology, Wuhan, China \\ Email: 1658260817@qq.com
}

How to cite this paper: Dong, Y.H. and Gao, Y. (2017) The Protection and Inheritance of Ancient Dwellings in Liu Jiaqiao Village under the Change of Times. Journal of Building Construction and Planning Research, 5, 71-83.

https://doi.org/10.4236/jbcpr.2017.52006

Received: April 20, 2017

Accepted: June 12, 2017

Published: June 15, 2017

Copyright $\odot 2017$ by authors and Scientific Research Publishing Inc. This work is licensed under the Creative Commons Attribution International License (CC BY 4.0). http://creativecommons.org/licenses/by/4.0/

\begin{abstract}
In this paper, the author takes the ancient dwellings in Liu Jiaqiao Village as an example to excavate its protection value. Meanwhile, the changing reasons of the dwellings are analyzed. Based on the analysis, the strategies dealing with the phenomenon are proposed from the perspective of protection and inheritance.
\end{abstract}

\section{Keywords}

Liu Jiaqiao, Ancient Dwellings, Protection, Inheritance

\section{Introduction}

Liu Jiaqiao is a village located in the Hubei Province, in the southern China. The blood type settlement of royal family is characterized by a series of dwellings built between the Ming Dynasty (last decades of 17th century) and 1833. The high significance of these buildings dwells in the historical, artist and scientific values that they have been carried through the centuries in a closelink with the environment and the landscape. Today the dwellings state of conservation is compromised from a material point of view and because the contemporary society and lifestyle are quite different from those of the dwellings construction time. The contribution proposes a strategy for the conservation and transmission to the future of this Chinese built heritage.

\section{The Protection Value of Ancient Dwellings in Liu Jiaqiao}

\subsection{Historical Value}

The village of Liu Jiaqiao was founded by Liu Bochang who was the 59th grandson of Liu Jiao, the King of Pengcheng [1]. Because of the fertile land and good 
Fengshui, he took his little son Liu Ruhe to settle down there. The earliest buildings Pengcheng Shijia, Xia Chang (factory for paper making), Hegao School and Feng Yuqiao (wind and rain bridge) were constructed at the same time. Later, Liu Ruhe's second son Liu Shihong lived apart and built the dwelling Shang Xinwu. And finally, his great grandson Liu Daben constructed another dwelling named Xia Xinwu. All the buildings were completed until 1833. Liu Jiaqiao village is a blood type settlement of royal family and $90 \%$ of the residents are with the family name Liu, which is quite rare in China. It went through two feudal dynasties Ming and Qing. As a result, it carries abundant of typical history information. Moreover, the ancient dwellings are not renovated massively, which provides more reference value [2]. Besides, the village was famous for its literature atmosphere. Thus, the cultural information the village carries makes its historical value more outstanding.

\subsection{Artistic Value}

The artistic value of the ancient dwellings in Liu Jiaqiao village is mainly reflected in the following aspects:

- The perfect fusion with nature: The ancient dwellings are located among green mountains and clear water. Lush vegetation and clear water of the river are set off against each other, vivid and graceful. The basic color of the dwellings is mainly grey and white, simple but elegant. Thus, the buildings are perfectly integrated into nature, which is full of beauty of harmony (Figure 1).

- Exquisite architectural decoration: The decoration of the ancient dwellings is of elegant simplicity. The elevation is decorated with coin shaped stone windows with distinctive local characteristics (Figure 2). Adding to the corbel-steps, the elevation is thus full of sense of rhythm. The wood carving of the attic in the patio is subtle, which reflects the wisdom of ancient craftsmen in China (Figure 3). There are a great number of plaques in the ancient dwellings. They were mainly given by the state government. The fonts are dignified and provide a strong cultural atmosphere (Figure 4).

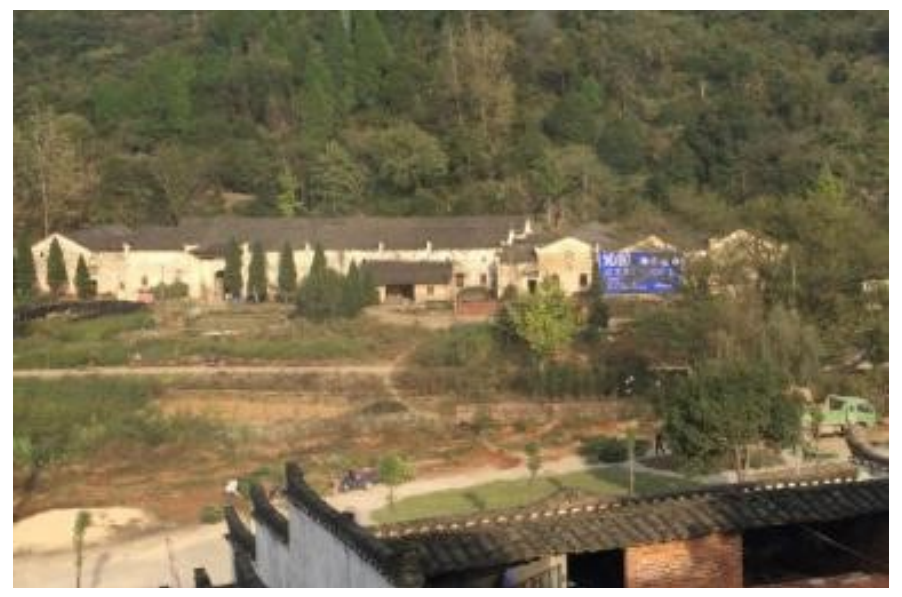

Figure 1. The perfect fusion with nature. 


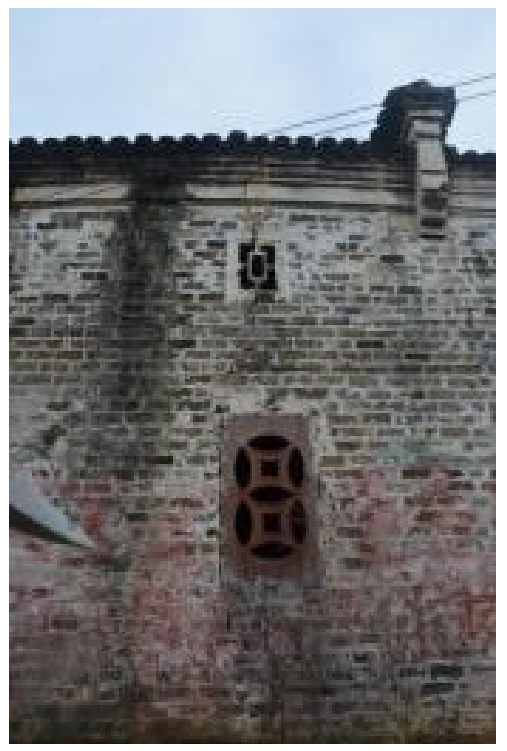

Figure 2. Coin shaped stone window.

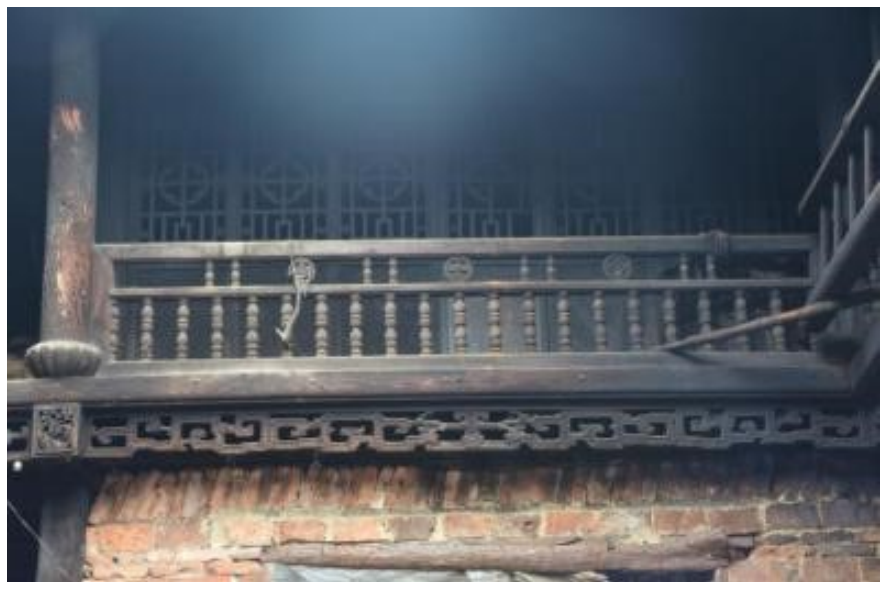

Figure 3. The wood carving of the attic.

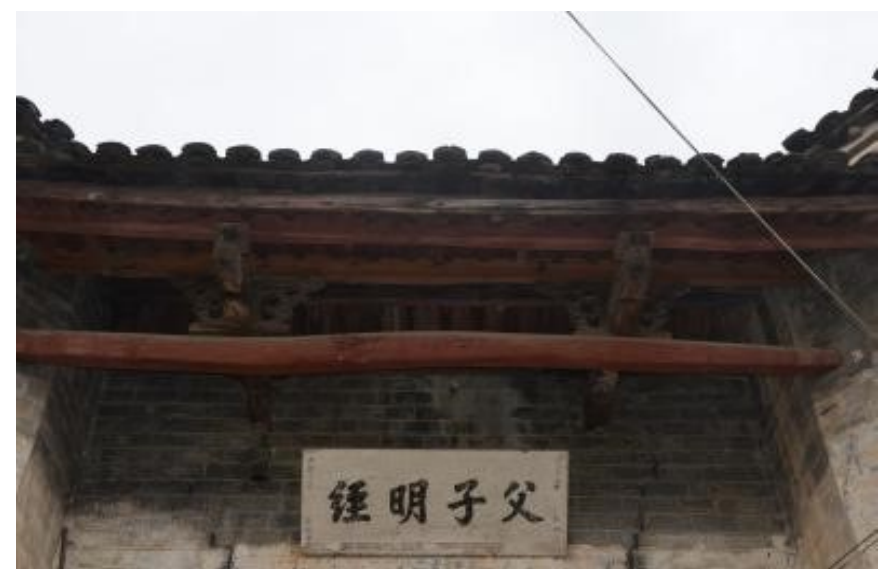

Figure 4. The plaque.

- The creative source of the works of art: The beautiful scenery of Liu Jiaqiao village and the unique buildings attract large numbers of students and artists 
to come for paintings. Meanwhile, some directors also come to make movies. Many films choose the village as the filming base. Liu Jiaqiao village has become the creative source of the works of art. In other words, the village has great artistic value that is hard to measure.

\subsection{Scientific Value}

During the construction of the ancient dwellings in Liu Jiaqiao village, elements such as environment and space were closely considered. Therefore, such dwellings with vivid space and great livability are constructed. Their construction is full of wisdom which can be referred by the modern architecture design.

- Respect for the original environment: Firstly, the respect for the original environment is reflected in the adaption of the terrain conditions. Taking Pengcheng Shijia as an example, the dwelling is constructed on the slope and the spatial pattern presents ladder form rise which is adapted to the terrain conditions. The last courtyard is of the highest terrain and its status is also the highest (Figure 5). The adaption of terrain highlights the central axis through the climbing of steps, which creates a strong worship atmosphere (Figure 6). In this way, not only the space is successfully created, but also great earthwork is saved. Moreover, the protection of trees is also an aspect of respect for the original environment. Ancient people treasured trees a lot. The old trees before Pengcheng Shijia and Xia Xinwu are the best evidence (Figure 7). It is the trees that regulate the micro environment of the dwellings. Therefore, a suitable living environment for the residents is provided.

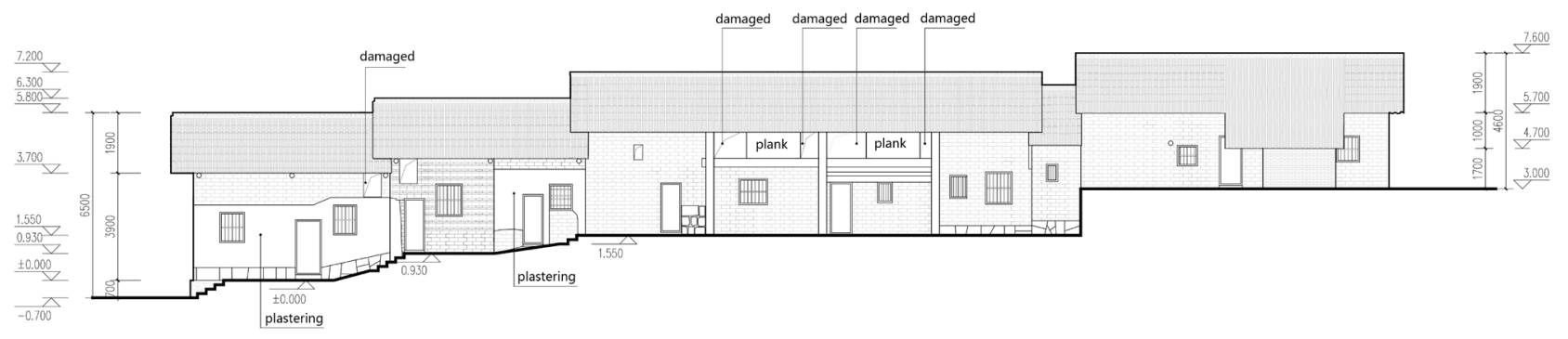

Figure 5. The adaption to the terrain conditions.

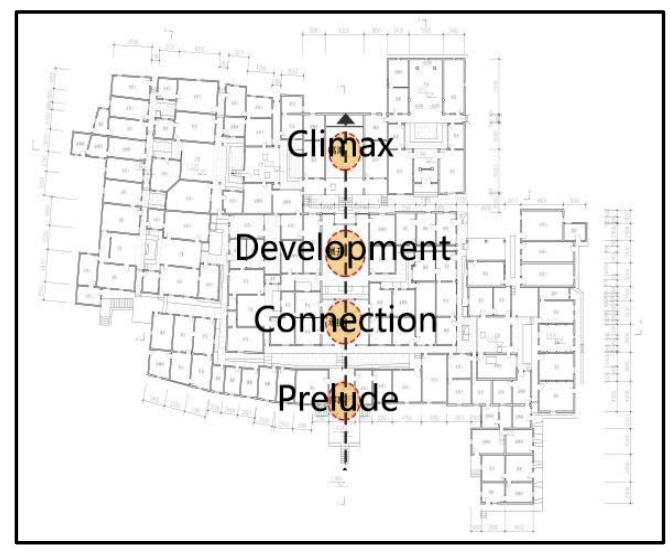

Figure 6. The creation of worship space. 


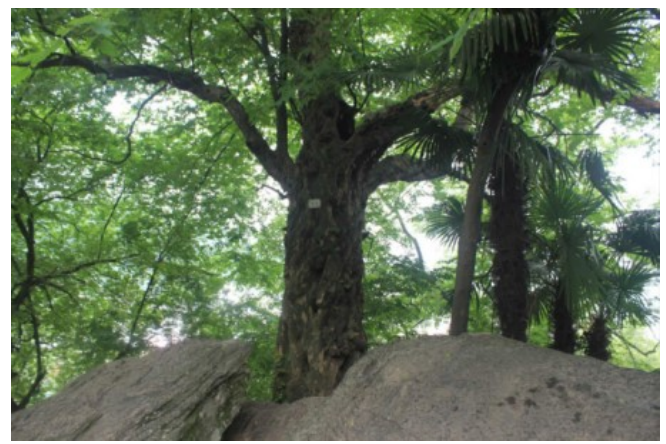

Figure 7. The old trees.

- Reasonable site selection and layout: The first aspect is site selection of the village. Influenced by the culture of Fengshui, the site selection is highly regarded. The site with good Fengshui is usually embraced by mountains, which gives people a strong sense of safety. Liu Jiaqiao village is surrounded by mountains from all directions and protects its villagers year by year. Fengshui has its scientific explanation. The mountains prevent the winter winds and enemies, which is suitable for living. That is how the sense of safety appears. Moreover, due to the restriction of the narrow terrain conditions, the dwellings cannot form the best orientation towards the south. But the dwellings rely on the mountains and face to the river, trying to create the best living environment under the limited conditions. Besides, the dwellings also have a wisdom of going after profit and avoiding harm. The house base is near the river but not closely enough to avoid the flood and meet the needs of living and production (Figure 8).

- Application of the patio space: The layout of patio combination is adapted to the local climate and social environment, which is of strong scientific value (Figure 9). In order to deal with the hot weather in summer, the patio can generate wind uplift effect and strengthen the ventilation [3]. Thus, the room temperature is reduced. The scale of the patio space is also cordial and pleasant, its area is mostly 15 - 20 square meters. It not only meets the need for daily activities, but also gives residents sense of belonging. Meanwhile, the patio extends eaves, together with the allies which also has extending eaves combines the rooms together. As a result, the residents' activities are not restricted by weather. Besides, the enclosure mode of the patio relates the ancestral hall and the family theater which provides public activities together (Figure 10). In this way, the big family maintained by blood can be stable, which is adapted to the feudal social environment at that time.

\section{The Changing Phenomenon and Reasons of the Ancient Dwellings}

Hundreds of years, the ancient dwellings were in a dynamic ecological balance. Their layout and style did not change evidently. However, with the change of times, the environment and social background has changed a lot. These factors disturb the balance of the ancient dwellings and a series of unprecedented 


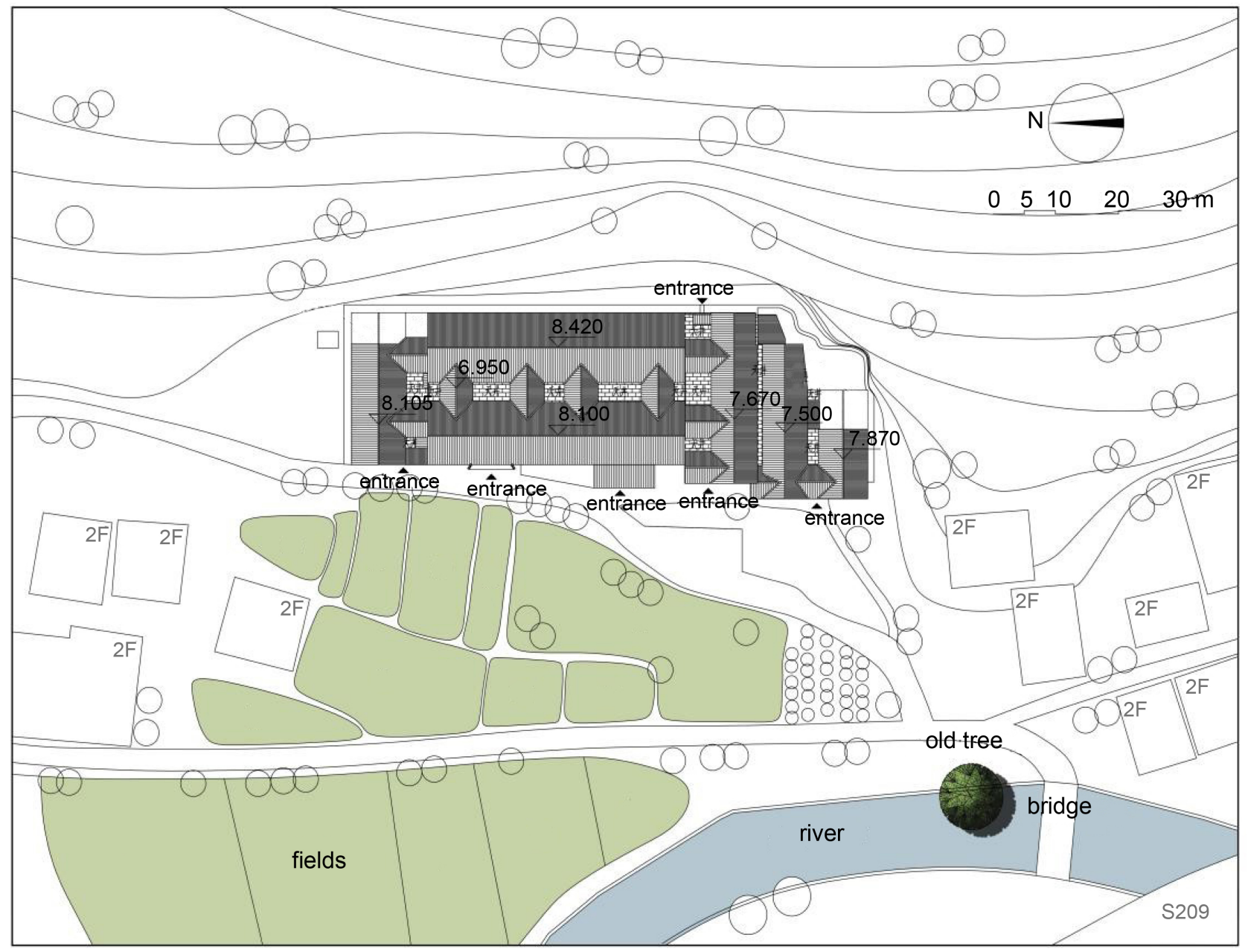

Figure 8. Site plan of Xia Xinwu.

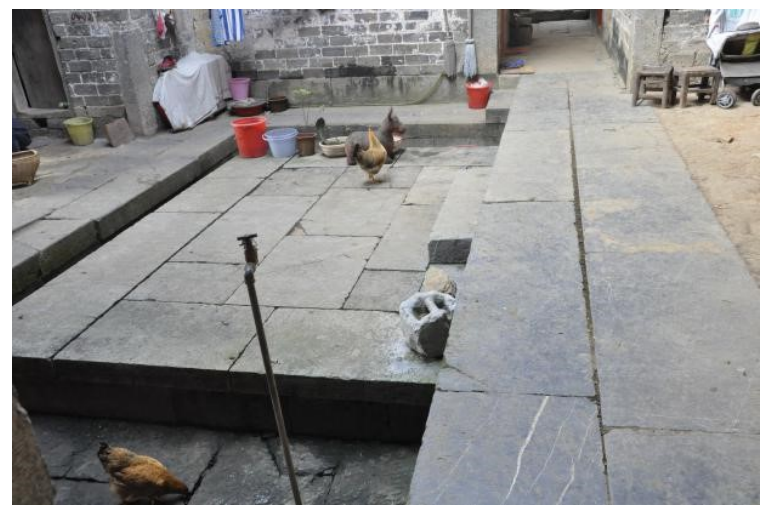

Figure 9. The patio space.

problems appear.

First is the disintegration of the large family with ties of blood. The implementation of the family planning policy in China makes the traditional large families change into small ones. Therefore, the concept of blood becomes indifferent. The ancestral hall is piled with sundries and the lively theaters are also abandoned (Figure 11). 
Moreover, the space of ancient dwellings is not suitable for the modern life. There used to be big families living in the dwellings, but nowadays different small families live in one dwelling at the same time. This is bound to lead to inconvenience of residents' life. Therefore, transformation without permission is commonly seen. The construction quality and sanitary conditions are poor as well (Figure 12). Besides, such big ancient dwellings need high maintenance costs which most residents cannot afford. As a result, residents use poor maintenance method or let it collapse with indifference. Thus, the overall appearance of the ancient dwellings is badly damaged (Figure 13 \& Figure 14).

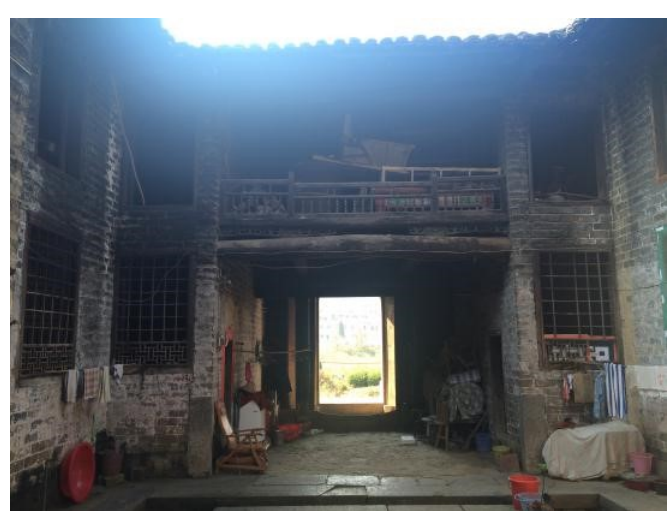

Figure 10. The family theater.

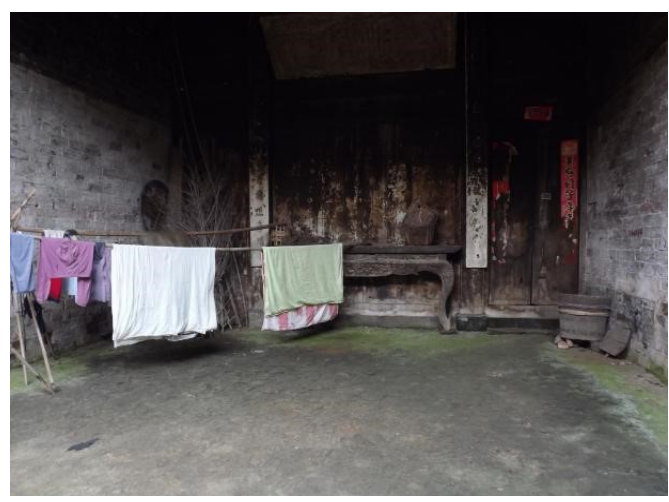

Figure 11. The ancestral hall piled with sundries.

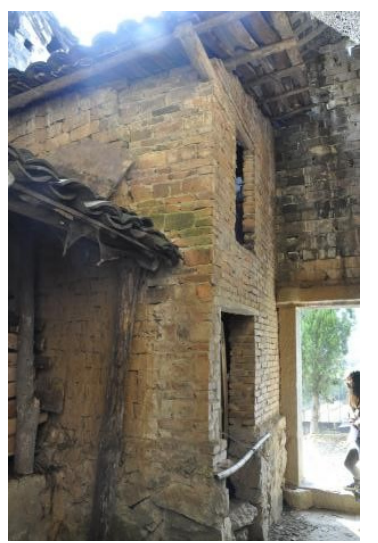

Figure 12. Transformation without permission. 


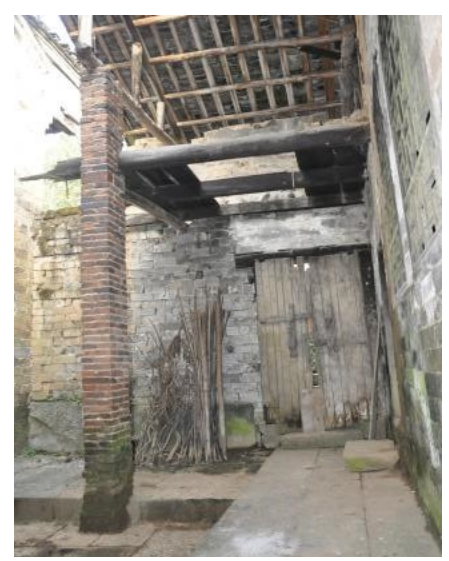

Figure 13. The poor maintenance.

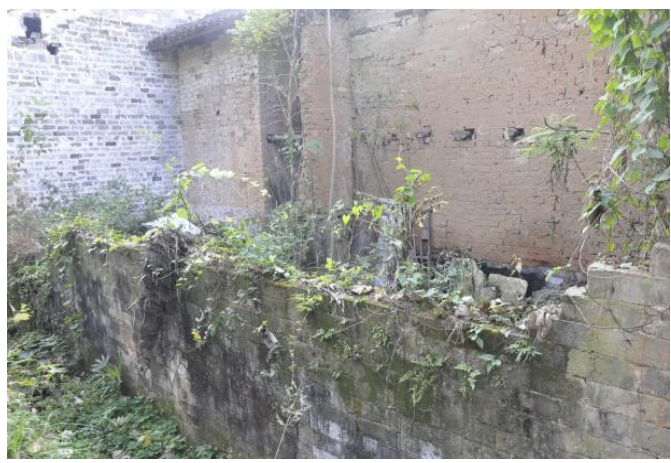

Figure 14. The damaged wall.

The influence of city is another important factor in the changes of the ancient dwellings in Liu Jiaqiao village. The construction of provincial road 209 breaks the isolation of the village, so the residents start to get in touch with the outside city (Figure 15). Young people are longing for the vigorous city life, rushing to the city to work, leaving the old and children (Figure 16). Due to the lack of young power and vitality, the village is doomed to decline.

It can be seen that the ancient dwellings in Liu Jiaqiao village are no longer adapted to the nowadays background. Without timely protection and inheritance, the ancient dwellings will suffer irreversible damage. New strategies to deal with the changes need to be proposed.

\section{Strategies of Protection and Inheritance Dealing with the Changes of Times}

In order to deal with the changes of times, strategies should be proposed from protection and inheritance.

\subsection{Protection}

\subsubsection{Restoration of the Ancient Dwellings}

As an important carrier of historical value, artistic value and scientific value, the protection of substantial remains is of great significance. However, disrepair and partly collapse is commonly seen. Without timely appropriate protection 


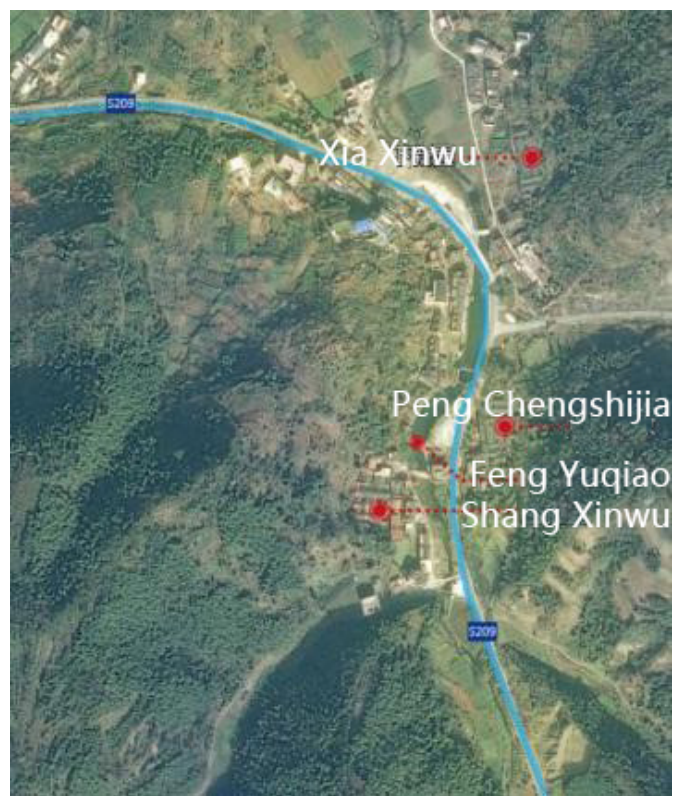

Figure 15. The location of provincial road 209.

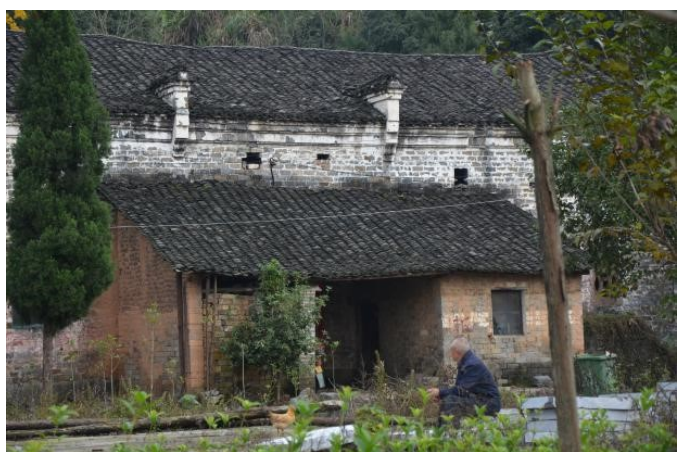

Figure 16. Lonely old man.

strategies, the ancient dwellings will eventually decline. If the material carrier no longer exists, the information it carries will also disappear, the protection will lose its rule and value. Thus, restoration is the basic of protection. The author participated in the restoration of one of the ancient dwellings Xia Xinwu. The following analysis will take it as an example.

Firstly, it is the evaluation of restoration criteria. The purpose of restoration is to maximize the preservation of the information the original building carries to maintain its authenticity. About authenticity, many protection rules are proposed, such as the "Venice charter" and "Nara Document on Authenticity" etc. Chinese heritage conservation specialist Ruan Yisan summarizes the protection rules about authenticity: The status of authenticity not only includes the state of the earliest construction, but also includes the subsequent restoration [4]. In other words, all the valuable historical information presents the status of authenticity. Therefore, the restoration should respect the current situation, keeping the historical information as much as possible under the ensuring of structure safety and normal use of the building. 
As to Xia Xinwu, three aspects of restoration are adopted.

- Control of structure and the envelope disease: The structure is the basic to maintain the material entity and the envelope is an important part of the normal use. So the restoration of the two should be put on the agenda. The diseases are summarized according to roof, wood frame, walls, floor etc. Typical photos of the diseases are taken and control strategies are proposed.

- Restoration of the housing pattern: Housing pattern reflects the age and geographical characteristics of the dwellings. However, the housing pattern of the ancient dwellings is badly damaged due to the changes of times. A lot of valuable information is covered, so it is of great importance to restore the housing pattern of the ancient dwellings. The transformation without permission which blocks the patio should be removed. Moreover, the collapsed part should be restored. The new tiles should be replaced by traditional grey tiles as well. In this way, the traditional style of Xia Xinwu is regained (Figure 17 \& Figure 18).

- Restoration of decorative components: Decorative components reflect the artistic value of the ancient dwellings, which are the crystallization of the wisdom of the ancients. The restoration of the decorative components will enable us to understand the ancient art more intuitively. The restoration mainly includes the damaged part of the components and the missing ones, referring to the decorative part elsewhere of the dwelling or other ancient dwellings in the village. In the restoration, the new parts coordinate with the style of the dwelling from the far view, but different from the old parts when coming near. Thus, the authenticity of the ancient dwelling is respected fully.

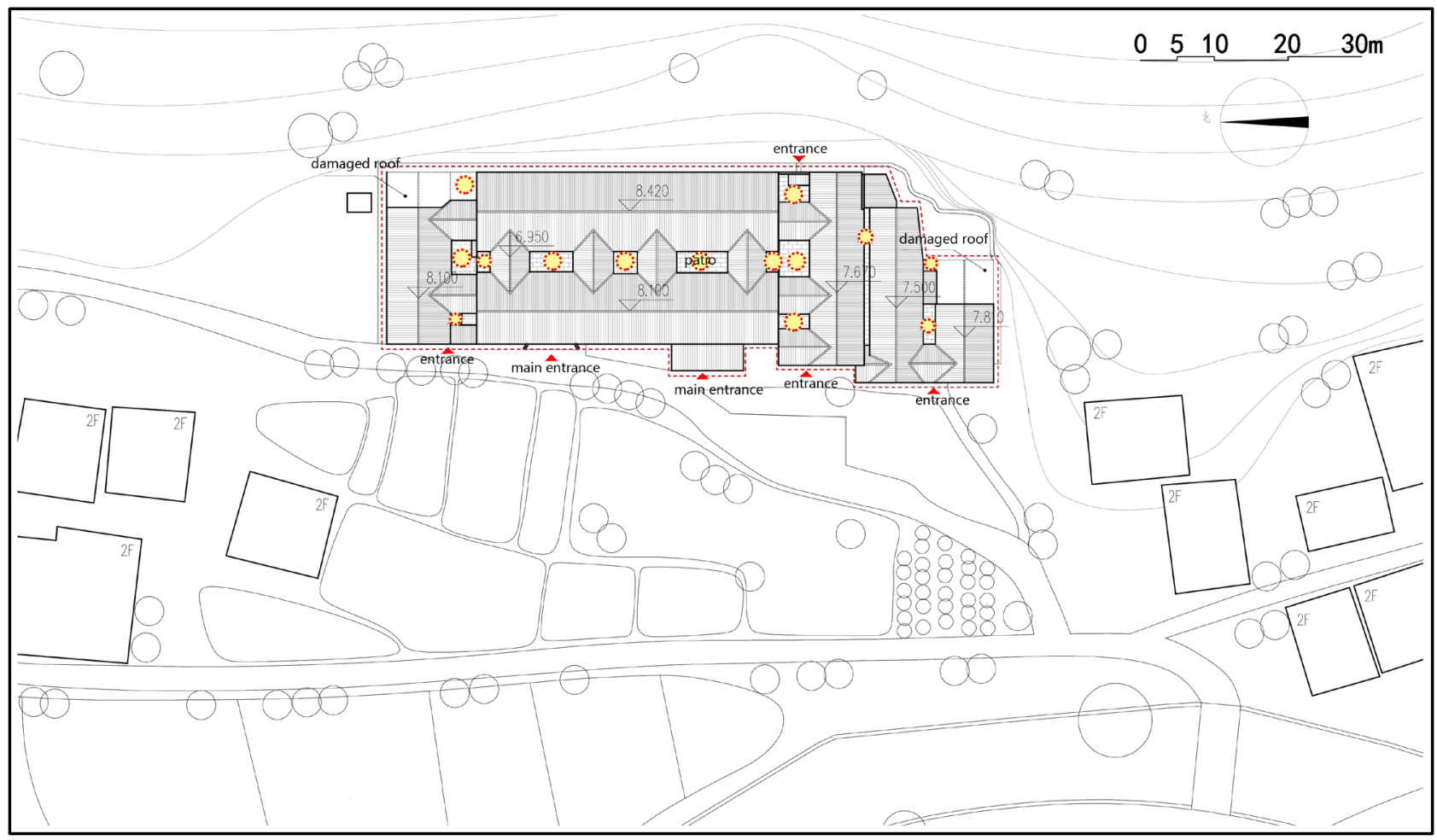

Figure 17. Housing pattern before restoration. 


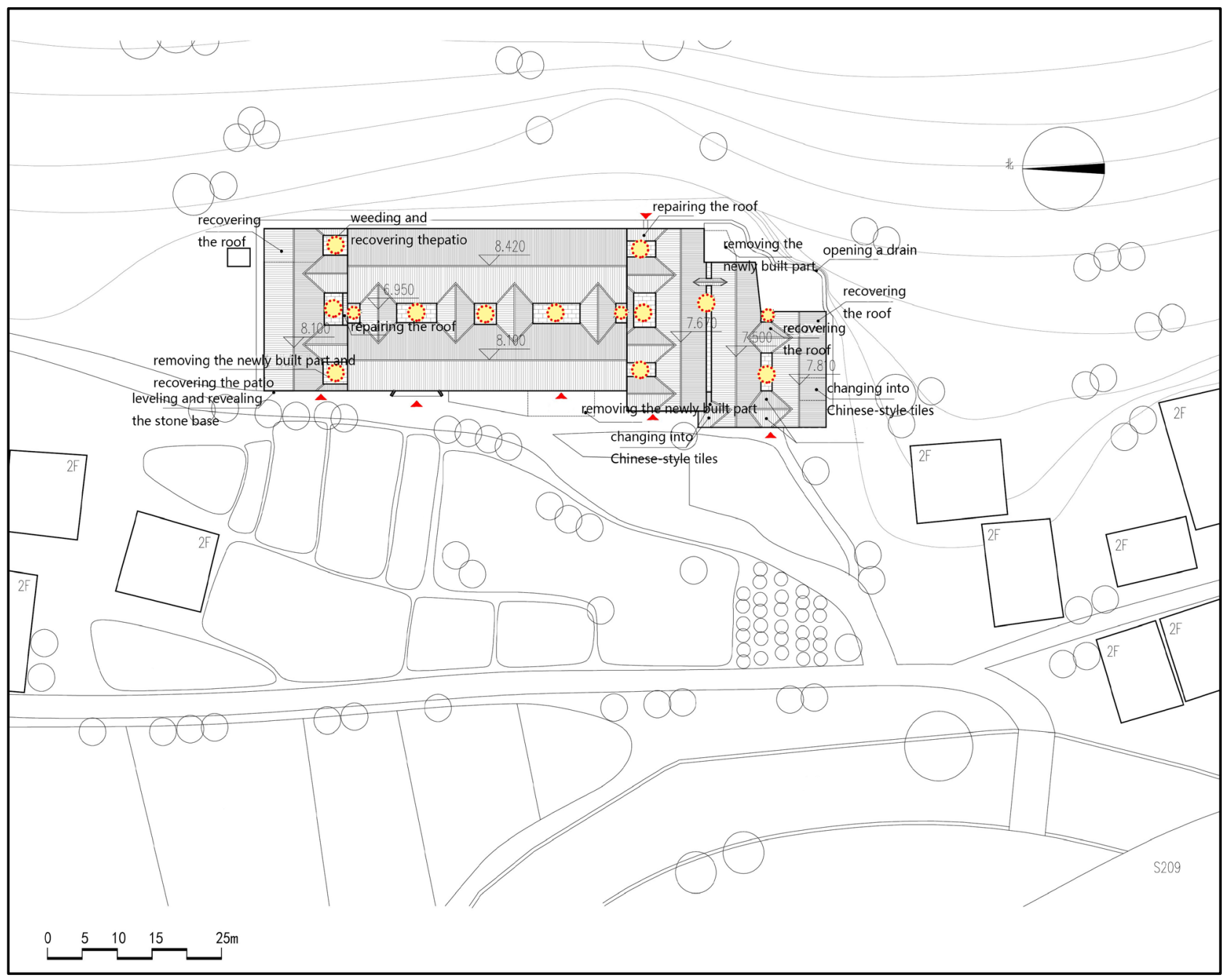

Figure 18. Housing pattern after restoration.

\subsubsection{Retain the Indigenous People}

The protection of material entity is only the basic requirement of protection. A house without activities will not be conducive to the remodeling of vitality. Therefore, moving the indigenous people out to develop tourism is totally wrong. As the users of the ancient dwellings, the indigenous people produce activities. So retaining the indigenous people is the key to keep the vitality of the ancient dwellings [5]. As is discussed in the former parts, the young people with vitality go to the city, leaving children and the old in the village. This leads to aging and hollow of the village. Thus, how to keep the young people in the village is the basic to solve these problems. According to the situation, the following strategies are proposed: Schools should provide courses of regional culture education to cultivate a sense of pride of native culture so that people love to stay at the village. As to the young adults, the beautiful scenery and fertile land provides opportunities for farm stay and organic agriculture which produces enough jobs to settle down. The transformation of the ancient dwellings is also an important strategy to retain the indigenous people. The traditional dwellings are no longer adapted to the modern life, so residents can transform the space 
under the guidance of experts. In this way, the residents can lead a more comfortable life and the basic pattern of the ancient dwellings is not damaged. Moreover, the government should also improve the environment quality and infrastructure to make the residents' life more convenient. Gradually, the outflow of young residents will be reduced and the vitality of the ancient dwellings will be improved.

\subsection{Inheritance}

Inheritance is the embodiment of a deeper level of protection. Protection keeps the material information and traditional way of life, while inheritance is the development of culture. Inheritance includes the connotation of the following two aspects.

\subsubsection{Inheriting the Folk Activities, Maintaining the Regional Characteristics}

The ancient dwellings of Liu Jiaqiao not only provide their material value, but also consist of the excellent culture of South Hubei. The inheritance of folk activities enables us to understand the social background of the dwellings' construction and the correlation between behavior and space [6]. Thus, it is more conducive to maintain the regional characteristics and enhance the cohesion of the residents, which leads to great development.

There are many kinds of folk activities in Liu Jiaqiao village, such as stepping on the lotus boat, playing the dragon lantern etc. The activities are of regional characteristics and combine the tradition of the Liu family, so the inheritance is of great significance. The old who are familiar with these activities can organize regular folk activities so as to promote exchanges with the outside. In this process, they will also enjoy themselves. Schools should also regularly organize children to participate in such activities, to achieve the purpose of cultural inheritance. In this way, children, the old and young adults will live in harmony which leads to steady development of the village.

\subsubsection{Using Traditional Construction Wisdom to Guide the Contemporary Architectural Design}

The construction wisdom of Liu Jiaqiao village is broad and profound. Some is not out of date even from the view of modern people, which is worth inheritance. The inspiration of traditional construction wisdom of Liu Jiaqiao village to the contemporary design can be summed up as follows:

1) Reasonable location and layout in order to deal with the regional climate conditions.

2) Contrasts the space atmosphere by using the terrain conditions.

3) Ventilation and shading through the patio to reduce energy consumption.

4) Using continuous grey space to increase the spatial mobility and level.

5) Pleasant and friendly scale instead of large scale.

6) Shape design coordinates with the environment, not exaggerated.

\section{Summary}

With the change of times, more and more excellent traditional houses gradually 
decline, so the protection of the ancient dwellings is of great significance. The protection of ancient dwellings is not limited to the traditional material restoration, but the traditional way of life of the residents should also be included in the scope of protection. The purpose of protection is inheritance. Inheritance of folk culture can continue the regional features so that the ancient dwellings and villages can develop healthily. The inheritance of the construction wisdom will help to explore the living environment with Chinese characteristics. Through protection and inheritance, the cultural heritages like the ancient dwellings in Liu Jiaqiao will regain their vitality.

\section{Acknowledgements}

This research is based on the restoration project of ancient dwellings in Liu Jiaqiao, Xianning, Hubei, China.

\section{References}

[1] Liu, M.H. (2015) The Ancient Charm-Tour of Han Royal Village Liu Jiaqiao. The Yellow River Press, Jinan.

[2] Zhang, L.G. (2002) Seven Says of the Carpenter. China Architecture \& Building Press, Beijing.

[3] Liu, D. (2008) Courtyard Space of Traditional Houses in Liujiaqiao of Southern Hubei Province. Huazhong Architecture, Vol. 26, No. 4.

[4] Ruan, Y.S. and Li, H.Y. (2008) Architectural Heritage Conservation in China from View of Authenticity. Huazhong Architecture, Vol. 26, No. 4.

[5] Li, X.F. (2005) Vernacular Architecture: Theory and Method of Interdisciplinary Research. China Architecture \& Building Press, Beijing.

[6] Hu, Y. (2011) Research on the Sustainable Development of Settlement Built Environment for Rural Tourism in Xian Ning. Huazhong University of Science and Technology, Wuhan.

Submit or recommend next manuscript to SCIRP and we will provide best service for you:

Accepting pre-submission inquiries through Email, Facebook, LinkedIn, Twitter, etc. A wide selection of journals (inclusive of 9 subjects, more than 200 journals)

Providing 24-hour high-quality service

User-friendly online submission system

Fair and swift peer-review system

Efficient typesetting and proofreading procedure

Display of the result of downloads and visits, as well as the number of cited articles

Maximum dissemination of your research work

Submit your manuscript at: http://papersubmission.scirp.org/

Or contact jbcpr@scirp.org 